\title{
EFFICACY OF TAMSULOSIN IN PATIENTS WITH BENIGN PROSTATIC HYPERPLASIA IN TERMS OF TRIAL WITHOUT CATHETER, A RANDOMIZED CONTROL TRIAL
}

Farhan Khana, Usman Qamara, Muhammad Saifullahº, Muhammad Sheraz Javed ${ }^{\mathrm{b}}$, Ahsan Ali Arainc, Muhammad Sohaild, Murli Lale

aLecturer, Department of Urology Sindh Institute of Urology and Transplantation, Karachi.

bSenior Registrar, Department of Urology, District Head Quarter Hospital / Faisalabad Medical University.

'Registrar, Department of Urology, Liaquat University Hospital, Hyderabad / Jamshoro.

${ }^{\mathrm{d} A s s o c i a t e}$ Professor, Department of Urology Aziz Fatima Medical and Dental College, Faisalabad.

eProfessor Department of Urology, SIUT, Karachi.

\begin{abstract}
:
BACKGROUND \& OBJECTIVE: Benign prostatic hyperplasia (BPH) is a prevalent cause of voiding problems in older males and is most commonly associated with acute urological complications, most important of which is acute urinary retention (AUR). a1-antagonists are the treatment of choice for the management of patients with BPH. Our objective was to evaluate the efficacy of tamsulosin for the treatment of patients with AUR due to BPH in terms of trial without catheter (TWOC).
\end{abstract}

METHODOLOGY: This randomized control trial was conducted in a Urology Section, Department of Surgery, SIUT Karachi, from 21-12-2016 to 20-06-2017.Our study included 136 patients who presented AUR due to BPH as per selection criteria. Patients were randomized into two groups. Group A patients received tamsulosin $(0.4 \mathrm{mg})$, and group B patients received placebo drug immediately after insertion of Foley catheter. The success of TWOC was evaluated after 3 days of medical treatment. Statistical analysis was carried out using SPSS v20.0.

RESULTS: The mean age of the study patients was $59.45+8.05$ years. The mean duration of BPH disease was $15.39+6.84$ months. There were $33(48.5 \%)$ patients in the tamsulosin group in which TWOC was successful and only 22 (32.4\%) patients in placebo group in which TWOC was successful ( $p$-value 0.04). There was no effect of age and duration of BPH disease on the outcome of this study.

CONCLUSION: Tamsulosin is effective for the treatment of patients with AUR due to BPH.

KEYWORDS: Benign Prostatic Hyperplasia, Urinary Retention, Tamsulosin.

\section{How to cite this:}

doi: https://doi.org/10.37723/jumdc.v12i3.558

Khan F, Qamar U, Saifullah M, Javed MS, Arian AA, Sohail M, et al. Efficacy of Tamsulosin in Patients with benign prostatic hyperplasma in terms of trial without catheter, a randomized control trial. Journal of University Medical \& Dental College. 2021;12(3):198-203. doi: https://doi.org/10.37723/ jumdc.v12i3.558

This is an Open Access article distributed under the terms of the Creative Commons Attribution License (http://creativecommons.org/licenses/by/4.0), which permits unrestricted use, distribution, and reproduction in any medium, provided the original work is properly cited. 


\section{INTRODUCTION:}

Benign prostatic Hyperplasia (BPH) is a common cause of voiding dysfunction in men. The prevalence of this disease increases with advancing age. The incidence of $\mathrm{BPH}$ is more than $80 \%$ in men having age above 70 years [1]. Prostate enlargement impairs physiologic and functional status and interferes with daily life routine. BPH is rarely a life-threatening condition and is most commonly associated with acute urological complications, most important of which is acute urinary retention (AUR), which is defined as sudden and painful inability to void voluntarily ${ }^{[2]}$. Urethral catheterization is considered a gold standard treatment for the management of acute urinary retention [3]. Catheterization is an avoidable risk factor of bleeding after transurethral resection of the prostate (TURP). So, a trial without a catheter (TWOC) is preferable instead of leaving the catheter in place. The success rate of TWOC is reported to be $28 \%{ }^{[4]}$.

Nowadays, a-1 receptor antagonists are the treatment of choice for the management of patients with $\mathrm{BPH}^{[5]}$. a-blockers reduce bladder outlet resistance, improve flow rate and help in emptying the urinary bladder ${ }^{[6]}$. Some studies have concluded that use of alpha blockers such as Tamsulosin can prevent the occurrence of acute urinary retention in the follow up period and thus can avoid the need of repeated catheterization and surgery ${ }^{[7]}$.

In one study the success rate of trial without catheter (TWOC) in the Tamsulosin group was $48 \%$ and in the placebo group was only $24 \%$ [8]. But we did not find any study conducted in Pakistan on the efficacy of Tamsulosin in patients of BPH in terms of successful TWOC in our population. Therefore, we conducted this study in patients with acute urinary retention in a tertiary care center to find out the efficacy of tamsulosin in the management of AUR. So those better therapeutic measures can be used in future for the welfare of patients based on the results of this study. The objective of the study is to evaluate the efficacy of Tamsulosin for the treatment of patients with AUR due to $\mathrm{BPH}$ in terms of TWOC.
Corresponding Author:

Dr. Muhammad Saif

Senior Registrar, Department of Urology,

DHQ Hospital/Faisalabad Medical University, Faisalabad.

Email:drsaif1987@gmail.com

\section{METHODOLOGY:}

This randomized control trial was conducted at a Urology section, Department of Surgery, Sindh Institute of Urology and Transplantation (SIUT), Karachi, from 21-12-2016 to 20-06-2017. The study has been approved by the ethical review committee of Sindh Institute of Urology and Transplantation (Ref\# SIUT-IRB-152).

We enrolled a total number of 136 patients who presented with acute urinary retention (AUR) due to BPH for the first time, for which perurethra catheterization was done, having age 40-70 years. Patients with a previous history of stricture urethra, prostatic surgery, urethral intervention, active hematuria, infection, traumatic catheterization, BPH with complications and prostatic malignancy were excluded from the study. Patients were randomly allocated into two equal groups ( 68 in each group) by the draw randomization method. Group A: allotted to patients in whom tamsulosin $(0.4 \mathrm{mg})$ was given immediately after insertion of foley catheter and Group B (control group): allotted to the patients in whom placebo drug was given after insertion of foley catheter. Foley catheter was removed after a period of 3 days after starting the medical treatment, and trial without catheter (TWOC) was evaluated. Successful TWOC was defined as patient voiding after TWOC without the need for catheterization upto one month. Data analysis was carried out using SPSS v20.0. Chi-square test was applied to compare the success of TWOC in the Tamsulosin group and Placebo group. Post-stratification Chi-square test and Fisher Exact test was applied, taking p-value $<0.05$ as significant.

\section{RESULTS:}

In this study, a total number of 136 patients were included with a mean age of $59.45+8.05$ years. The minimum age was 40 years, and the maximum age was 70 years. The mean duration of $\mathrm{BPH}$ disease was $15.39 \pm 6.84$ months. 
The minimum duration of BPH symptoms was one month, and the maximum duration was 24 months,i.e.,2 years (Table-I).

Table-I: Descriptive Statistics.

\begin{tabular}{|c|c|c|}
\hline Variables & Mean & $\begin{array}{c}\text { Standard } \\
\text { Deviation }\end{array}$ \\
\hline Age (Years) & 59.45 & 8.05 \\
\hline $\begin{array}{c}\text { Duration of } \\
\text { symptoms (months) }\end{array}$ & 15.39 & 6.84 \\
\hline
\end{tabular}

The trial without catheter (TWOC) was successful in $55(40.4 \%)$ patients and was unsuccessful in $81(59.6 \%)$ patients. There were $33(48.5 \%)$ patients in Tamsulosin group in which trial without a catheter was successful, and only $22(32.4 \%)$ patients in placebo group in which trial without catheter (TWOC) was successful. Moreover, this difference in TWOC success rate between the groups was statistically significant (p-value 0.040) (Table-II).

Table-II: Cross tabulation among group and TWOC.

\begin{tabular}{|c|c|c|c|c|c|}
\hline & & & \multicolumn{2}{|c|}{ TWOC } & \multirow[t]{2}{*}{ Total } \\
\hline & & & Unsuccessful & Successful & \\
\hline \multirow{4}{*}{ Groups } & \multirow{2}{*}{$\begin{array}{l}\text { Tamsulosin } \\
\text { Group }\end{array}$} & $\mathrm{N}$ & 35 & 33 & 68 \\
\hline & & $\%$ & $51.5 \%$ & $48.5 \%$ & $100.0 \%$ \\
\hline & \multirow{2}{*}{$\begin{array}{l}\text { Placebo } \\
\text { Group }\end{array}$} & $\mathrm{N}$ & 46 & 22 & 68 \\
\hline & & $\%$ & $67.6 \%$ & $32.4 \%$ & $100.0 \%$ \\
\hline \multirow{2}{*}{\multicolumn{2}{|c|}{ Total }} & $\mathrm{N}$ & 81 & 55 & 136 \\
\hline & & $\%$ & $59.6 \%$ & $40.4 \%$ & $100.0 \%$ \\
\hline
\end{tabular}

Chi-square value $=3.694$

$\mathrm{p}$-value $=0.040$

Age stratification was done into two subgroups. In group-A (Tamsulosin), patients with age $<60$ years had successful TWOC in $45.5 \%(n=15)$ patients as compared to $54.5 \%(n=18)$ patients who were aged $>60$ years. However, in group B (placebo), patients aged $<60$ years had successful TWOC in $40.9 \%(n=9)$ as compared to $59.1 \%(n=13)$ in patients aged $>60$ years.

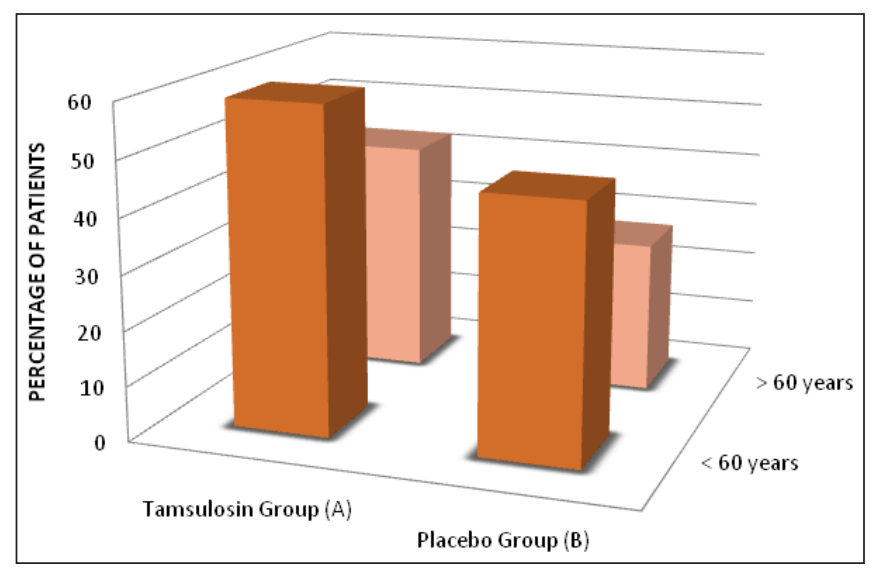

p-values are 0.040 which were insignificant (Figure-I).

Figure-I: Stratification of patients according to age.
We stratified the duration of BPH disease into three subgroups to determine the effect of duration of $\mathrm{BPH}$ disease on outcomes of the study. There was no effect of duration of disease on the success rate of TWOC in the both groups. In patients with the duration of $\mathrm{BPH}$ disease less than 6 months, there were $12.1 \%(n=4)$ cases of successful TWOC in the group A (Tamsulosin) and only $4.5 \%(n=1)$ case in group B (placebo). In patients with the duration of BPH disease 6 months to 12 months, there were $27.3 \%(n=9)$ cases of successful TWOC in Tamsulosin group and $22.7 \%(n=5)$ cases in Placebo group In patients with the duration of $\mathrm{BPH}$ disease $>12$ months, there were $60.6 \%(n=20)$ cases of success in Tamsulosin and only $72.7 \%(n=16)$ cases in Placebo group. 




(Figure-II)

Figure-II: Stratification of patients according to the duration of BPH symptoms.

\section{DISCUSSION:}

In our study, patients had a success rate of approximately $50 \%$ in the Tamsulosin group for not requiring re-catheterization upto one month, while the patients in the placebo group had a success rate of approximately $30 \%$. Moreover, individuals who have prescribed Tamsulosin for TWOC have 2.21 times higher odds of having a successful TWOC as compared to placebo.

In three studies, the requirement of recatheterization was used as a clinical tool to assess TWOC. Out of these, two studies compared alfuzosin with placebo and the third study compared Tamsulosin with Placebo. Both studies compared Alfuzosin with placebo taken for 24-hour post-catheterization. One of these studies was a pilot project, whereas the other was a randomized clinical trial involving multiple centers. Successful TWOC in these trials was declared in patients who had successful voiding after catheter removal and did not require re-catheterization ${ }^{[9]}$. In another interesting prospective study, alfuzocin was declared an efficient and safe option in patients presenting with AUR ${ }^{[10]}$.However, they did not assess the duration of preceding lower urinary tract symptoms. One study which compared Tamsulosin with placebo also found a significant effect of Tamsulosin on success of TWOC, with a success rate of $48 \%$ in the Tamsulosin group and only $26.0 \%$ in Placebo group. In this study, there was no effect of age on the success rate of TWOC ${ }^{[8]}$.

A prospective randomized study was conducted which compared Tamsulosin with silodosin and concluded comparable results in terms of successful TWOC[11]. In another study, Tamsulosin and alfuzosin were found to be effective for treatment of urinary retention and $\mathrm{BPH}{ }^{[12]}$. One recent study evaluated the predictors of successful TWOC after AUR and concluded that patients age, intravesical prostatic protrusion, prostate volume and residual volume are independent predictors of successful TWOC [13]. Assessment of severity of preceding LUTS using IPSS was found to be significantly associated with success of TWOC in one study [14].

Many studies have been conducted to assess the involvement of the autonomic nervous system and alpha receptors in establishing the pathophysiology of benign prostatic enlargement. The studies have made way for clinical trials that assessed the use of a-1 adrenergic receptor (a-1 AR) antagonists to treat lower urinary tract symptoms (LUTS) caused by enlargement of the prostate. These studies concluded that a-1 AR antagonists relax the smooth muscles present in the prostate, thereby relieving the voiding LUTS and improving the urine outflow. Additionally, a-1 AR blockers were also found helpful in improving storage LUTS, possibly due to a reduction in post-void residual urine $[15,16]$.

On the basis of the analysis of the involvement of a-1 ARs and the evidence provided by the available clinical trials in which a-1 AR blockers were used, it is widely accepted that a-1 AR antagonist is the first-line treatment option for patients having LUTS secondary to BPH. a-1 ARare divided into subgroups which include $a-1 a, a-1 b$ and $a-1 d$ $[17,18]$. Out of theses mooth muscles of the vessels have $a-1 b$ AR ${ }^{[19]}$. Although all the three $a-1$ AR subtypes are present in the prostate, a-1a AR subtype is the predominant subtype when it comes to human prostatic smooth muscles ${ }^{[20]}$. One study has revealed that the a-1 AR present in the prostatic smooth muscles have $69 \%$ a-1a, $27 \%$ a-1d and $3.3 \%$ a-1b ARs ${ }^{[21]}$. However, one study reported that a-1a AR subtype in patients having $\mathrm{BPH}$ increased to $85 \%$. Therefore, the other two subtypes $\mathrm{a}-1 \mathrm{~d}$ and $\mathrm{a}-1 \mathrm{~b}$ reduced to $14 \%$ and $<1 \%$, respectively. Non-selective $a-1$ AR antagonists who were widely used previously 
had successful symptom control, but this efficacy was at the cost of the significant number of side effects caused by vasodilatation nor-adrenaline release. These included dizziness, orthostatic hypotension and syncope attacks attribut able to a-1b AR blockade and subsequent vasodilatation ${ }^{[22]}$. These side effects have significantly reduced by the use of subtype-selective a-1 AR blockers like Tamsulosin.

Several studies have also compared the longterm safety and efficacy of Tamsulosin for the management of symptoms of BPH and have found that once daily treatment with Tamsulosin is safe as well as effective for the management of patients with BPH.

Limitations of our study are the absence of follow up for a longer time duration andsmaller sample size. Another limitation of our study is that it lacks standardization according to intravesical prostatic protrusion, prostate volume and residual volume. Therefore, we suggest studies on a large scale with longer follow-ups.

Based on the results of present study and the existing literature, this can be concluded that Tamsulosin is a safe and effective drug for the acute and long-term management of patients with $\mathrm{BPH}$.

\section{CONCLUSION:}

Tamsulosin is an effective drug for the treatment of patients with acute AUR due to $\mathrm{BPH}$.

ACKNOWLEDGEMENT: None. GRANT SUPPORT \& FINANCIAL

DISCLOSURE: None.

CONFLICT OF INTEREST: All authors disclose no conflict of interest.

\section{REFERENCES:}

1. Wei JT, Calhoun E, Jacobsen SJ. Urologic diseases in America project: benign prostatic hyperplasia. The Journal of Urology. 2005; 173:1256-1261.

2. Billet $M$, Windsor TA. Urinary Retention. Emergency Medical Clinics of North America. 2019;37(4):649-660. Doi: 10.1016/j. emc.2019.07.005.

3. Serlin DC, Heidelbaugh JJ, Stoffel JT. Urinary Retention in Adults: Evaluation and Initial Management. American Family Physician. 2018;98(8):496-503.

4. Taube M, Gajraj H. Trial without catheter following acute retention of urine. The British Journal of Urology International. 1989;63(2):180-182.

5. Moon HW, Yang JH, Choi JB, Bae WJ, Cho HJ, Hong $\mathrm{SH}$, et al. Prescription pattern of alphablockers for management of lower urinary tract symptoms/benign prostatic hyperplasia. Scientific Reports. 2018;8(1):1-6.

6. Kim DK. Current pharmacological and surgical treatment of underactive bladder. Investigative and Clinical Urology. 2017; 58:90-98. Doi: 10.4111/icu.2017.58. S2.S90.

7. Akkoc A, Aydin C, Topaktas R, Kartalmis M, Altin $S$, Isen $K$, et al. Prophylactic effects of alpha-blockers, Tamsulosin and Alfuzosin, on postoperative urinary retention in male patients undergoing urologic surgery under spinal anaesthesia. International Brazilion Journal of Urology. 2016;42(3):578-584.

8. Lucas MG, Stephenson TP, Nargund V. Tamsulosin in the management of patients in acute urinary retention from benign prostatic hyperplasia. The British Journal of Urology International. 2005;95(3):354-357. Doi: 10.1111/j.1464-410X.2005.05299.x

9. McNeill SA, Daruwala PD, Mitchell ID, Shearer MG, Hargreave TB. Sustainedrelease alfuzosin and trial without catheter after acute urinary retention: a prospective, placebo-controlled trial. The Bristish Journal of Urology International. 1999;84:622-627.

10. Martov AG, Ergakov DV. The use of alfuzosin in the treatment of patients with acute urinary retention. Urologiia. 2020;(6):58-63.

11. Patil SB, Ranka K, Kundargi VS, Guru N. Comparison of tamsulosin and silodosin in the management of acute urinary retention secondary to benign prostatic hyperplasia in patients planned for trial without catheter. A prospective randomized study. Central European Journal of Urology. 2017;70(3):259-263.

12. Karavitakis M, Kyriazis I, Omar MI, Gravas S, Cornu JN, Drake MJ, et al. Management of urinary retention in patients with benign prostatic obstruction: a systematic review and meta-analysis. European Urology. 2019;75(5):788-798.

JUMDC Vol. 12, Issue 3, July-September, 2021 
13. Bansal A, Arora A. Predictors of successful trial without catheter following acute urinary retention in benign prostatic enlargement: A single centre, multivariate analysis. Neurourology and Urodynamics. 2017;36(7):1757-1762.

14. Farelo-Trejos OL, Paesano NE, Serna-Hurtado JJ, García MF, Monzó-Gardiner JI. Prognostic factors predicting failure of the trial without catheter after tamsulosin in patients with acute urinary retention. Archivos Espanoles De Urologia. 2017;70(9):759-765.

15. McNeill SA, Hargreave TB, Roehrborn CG, Alfaur Study Group. Alfuzosin $10 \mathrm{mg}$ once daily in the management of acute urinary retention: results of a double-blind placebocontrolled study. Urology. 2005;65(1):83-89. Doi: 10.1016/j.urology.2004.07.042.

16. Lepor H, Nieder A, Feser J, O'Connell C, Dixon C. Effect of terazosin on prostatism in men with normal and abnormal peak urinary flow rates. Urology. 1997;49(3):476-480.

17. Docherty JR. The pharmacology of a1adrenoceptor subtypes. European Journal of Pharmacology. 2019; 855:305-320. Doi: 10.1016/j.ejphar.2019.04.047.

18. Schwinn DA, Johnston GI, Page SO, Mosley $\mathrm{MJ}$, Wilson $\mathrm{KH}$, Worman NP, et al. Cloning and pharmacological characterization of human alpha-1 adrenergic receptors: sequence corrections and direct comparison with other species homologues. Journal of Pharmacology and Experimental Therapeutics. 2015;272(1):134-142.

19. Hwang EC, Gandhi S, Jung JH. New alpha blockers to treat male lower urinary tract symptoms. Current Opinion in Urology. 2018;28(3):273-276. Doi: 10.1097/ MOU.0000000000000488.
20. Chakrabarty B, Dey A, Lam M, Ventura S, Exintaris B. Tamsulosin modulates, but does not abolish the spontaneous activity in the guinea pig prostate gland. Neurourology and Urodynamics. 2015;34(5):482-488.

21. Nascimento-Viana JB, Carvalho AR, Nasciutti LE, Alcántara-Hernández $R$, ChagasSilva F, Souza PA, et al. New multi-target antagonists of $\mathrm{a} 1 \mathrm{~A}-$, $\mathrm{a} 1 \mathrm{D}$-adrenoceptors and 5-HT1A receptors reduce human hyperplastic prostate cell growth and the increase of intraurethral pressure. Journal of Pharmacology and Experimental Therapeutics. 2016;356(1):212-222.

22. Rudner XL, Berkowitz DE, Booth JV, Funk BL, Cozart KL, D'Amico EB, et al. Subtype specific regulation of human vascular a1-adrenergic receptors by vessel bed and age. Circulation. 1999;100(23):2336-2343.

\section{Author's Contribution:}

Farhan Khan: Designed the study, principal author \& manuscript writer.

Usman Qamar: Co-author, investigator, data Collector.

Muhammad Saifullah: Co-author, statistical, data analysis, substantial contribution to the conception.

Muhammad Sheraz Javed: Co-author and literature review.

Ahsan Ali Arain: Data collection and analysis. Muhammad Sohail: Drafting of work or revising it critical for important intellectual content.

Murli Lal: Research supervision.

Submitted for Publication: 14-02-2021

Accepted After revision: 18-04-2021 